\title{
Efficacy of Task-Based Learning in a Chinese EFL Classroom: A Case Study
}

\author{
Hersong Tang ${ }^{1}$, Jer-Shiou Chiou ${ }^{1} \&$ Oliver Jarsaillon ${ }^{2}$ \\ ${ }^{1}$ Faculty of Finance \& Banking, Shih Chien University, Taiwan \\ ${ }^{2}$ Faculty of Language Center, Shih Chien University, Taiwan \\ Correspondence: Hersong Tang, Department of Finance \& Banking, Shih Chien University, Taipei, Taiwan. Tel: \\ 886-2-2538-1111 ext. 8719. E-mail: hosong@g2.usc.edu.tw
}

\author{
Received: February 7, 2015 Accepted: March 9, 2015 Online Published: April 23, 2015 \\ doi:10.5539/elt.v8n5p168 URL: http://dx.doi.org/10.5539/elt.v8n5p168
}

\begin{abstract}
This study investigated how task-based learning (TBL) developed the verbal competence of Chinese learners of English as a foreign language (EFL) by employing qualitative and quantitative analyses. We compared the impromptu oral presentations on reading texts of 76 intermediate EFL learners given respectively in the beginning and the end of the 15 -week study period at a Taiwanese university. The findings revealed that TBL was effective in fluency, lexical and syntactic complexity, and ineffective in accuracy. Besides, a standardized pretest and a post-test of English proficiency were administered, apart from a students' self-report questionnaire at the end of the experiment. The results of the proficiency exams showed that students made significant improvements in reading and little improvement in listening after TBL. In the self-assessment of the effects of TBL, students felt improvements in vocabulary and pronunciation. Overall, TBL was motivational and useful for language acquisition. Learners' attention was directed to a reading text as a whole for communicative purposes, and therefore their receptive and productive competence was enhanced.
\end{abstract}

Keywords: task-based learning (TBL), linguistic development, language use, efficacy of TBL

\section{Introduction}

\subsection{The Disparity between Concepts and Language Expression of Taiwan's EFL Learners}

Based on the data released by Educational Testing Services from 2006 to 2013, the hardest part for Chinese examinees to score high points was the speaking section. Take Taiwanese EFL learners for example. They may excel at taking proficiency tests in the form of multiple-choice questions as they are accustomed to test-oriented pedagogy and focus on rote memorization. However, impromptu oral presentations and self-expression may appear challenging. This prevailing phenomenon has raised the attention of EFL instructors to identify techniques to help develop student's verbal competence. Considering the struggle of students between concepts and linguistic expression, we sought herein to develop oral competence that approximates as closely as possible the thinking of the Chinese EFL learner.

\subsection{L2 Input-Poor Environment and Learning for Communicative Purposes}

Given its educational system that encourages test-driven pedagogy; most EFL learners in Taiwan often do not have much access or chance to speak the target language. English in Taiwan has an "input-poor" environment where most communication both in and outside the English classroom is in the L1 (Kouraogo, 1993). Therefore, many universities provide courses aimed to help learners to communicate fluently in diverse contexts. However, in-class oral activities as employed in a Chinese EFL classroom like scripted role-play and prepared oral presentations are apparently counterproductive in the context of genuine, authentic use of the target language (Bruner, Sinwongsuwat, \& Radić-Bojanić, 2015).

Most linguists maintain that language learning involves the development of a learner's capacity for language utilization (Long, 1981; Krashen, 1985; Ellis, 2003). Given the spontaneous nature of ordinary conversation learners need to master, the target language "is best learned through the exposure and negotiation that occurs during the course of performing communicative tasks" (Ur, 2013). Language should be regarded as a means of communication. Interaction and communication is thought to play a determining role in the acquisition of the target language, and therefore, task-based learning (TBL) has drawn increasing attention as an alternative 
pedagogy in the EFL classroom.

\subsection{Definition of Tasks}

A common description of tasks is a communicative activity in which some exchange of information takes place to achieve a goal (Bygate, 1999; Ellis, 2003; Skehan, 2009). Breen (1989) stated that a task could be a brief practice exercise or a more complex work plan that requires spontaneous communication of a given meaning. Ellis (2003) maintained that the workplan require learners to employ a combination of receptive and productive skills to produce a written or oral report on a listening or reading text. Based on these findings, the task developed in the present study required participants to read a text of the textbook, google relevant information through both collaborative and individual work, and then produce an oral text for communicative purposes.

\subsection{Literature Review}

An abundance of studies have been conducted on TBL. Inside and outside of the ESL/EFL classroom, researchers have been examining TBL in terms of its efficacy. Advocates of TBL suggested that the best way to promote effective learning be by setting up classroom tasks that reflect the real-world tasks the learners will perform. This made TBL of particular value in the design and teaching of courses in English for Specific Purposes (ESP). Lynch and Maclean administered a "poster carousel" (2000) to investigate the benefits of TBL in an ESP course for health professionals who were tasked with presenting papers in English at international conferences. In that task, participants replied to questions posed by the visitors at their posters. Although the participants appeared to wrestle with the conceptual material and its linguistic expression during the first few task cycles, with more practice of answering questions by poster visitors, they gained increased familiarity with the vocabulary and thus achieved greater fluency. Lynch and Maclean found that the increased familiarity helped participants handle questions under time pressure and to repair breakdowns in communication. Besides, a comparison of the performance of two learners at markedly different levels of English proficiency revealed that even learners of limited proficiency were capable of incorporating the expressions of a partner into his or her own speech.

Outside the ESL classroom, Springer and Collins (2008) observed interactions between two adult ESL learners working as volunteer tutors and English-speaking children who were at risk academically, with the assumption that the nature of the oral interaction a learner experiences in real-world contexts differs from what is present in the language classroom, and that the real-world experience was capable of complementing the classroom experience. Initially, the protective 'bubble' of the language classroom did not prepare the adult ESL learners for unplanned events that increased the linguistic demand. After managing the execution of the different tasks and successfully completing them, these adult learners achieved a sense of how well their language was understood. They experienced joy when they relayed their message despite language errors. These adult learners attended to linguistic features of English through self-initiated reformulations and through providing and receiving language assistance, both solicited and unsolicited. These experiences validated the determining role played by interaction in the acquisition of a foreign language.

In Asia, researchers have also examined the role of TBL in language development. Park (2010) investigated whether pre-task instructions and planning promote a focus on lexical or grammatical language-related episodes during task-based interactions. In that study, the picture narrative tasks completed by 110 Korean EFL learners in regularly scheduled classes were examined over a period of two weeks. Park discovered that learners focused only on vocabulary and that pre-task instructions had a role in directing attention to lexical or grammatical language-related episode whereas planning had no effect.

Skehan, Xiaoyue, Qian, and Wang (2012) reported three studies in China and Hong Kong that examined the effects on task performance of planning and task repetition, familiarity with the material, and post-task transcription of the oral performance of learners, respectively. The framework of this work was based on oral tasks of students including narratives, description, comparison, and decision-making. The findings suggested that task repetition could be more potent in its effect than familiarity with the material and planning, and that planning and post-task transcription were associated with less error in performance.

\subsection{The Purpose of the Study}

Despite considerable efforts invested in the precedent studies, a number of questions are raised. Park (2010) spent two weeks studying the efficacy of pre-task instruction and online planning of EFL task-based interactions. That left us questioning if the learners could develop more linguistic competence after being provided with a longer experimental period? In the study by Springer et al. (2008), the two adult learners worked as tutors outside the classroom to complement their classroom experiences as language users. How could a learner 
become a language user capable of dealing with unplanned events outside the protective "bubble" of a conventional EFL classroom setting? Skehan (2012) held that repetition of a task had a potent effect on task performance. How could we incorporate repetition into tasks without boring students? Lynch and Maclean (1994) concluded that TBL have particular value in ESP. Would students also benefit from TBL in English for general purposes with larger scope of vocabulary to learn in a broader content?

The purpose of the study was to explore the following questions:

1) How does TBL facilitate linguistic development in a Chinese EFL classroom?

2) How does TBL help students improve on standardized proficiency tests besides verbal competence?

3) How do Chinese EFL learners perceive TBL?

\section{Method}

This empirical study was conducted for 15 weeks and comprised five stages. 1) Before the implementation of TBL, students took a General English Proficiency Test (GEPT) as the pre-test. 2) During the study period, all oral tasks of students were audio-recorded. Because of limited class time, tasks were performed only by group in each class session. Only in the first and last week respectively was each student required to give a 5-minute impromptu presentation, which served as the primary data source of this study. All recordings of the first and last weeks were then marked by another teacher of English for an objective assessment. 4) After 15-week implementation of TBL, a post-test of GEPT was administered. These pre- and post- proficiency tests served as aided research instruments to survey improvements. 5) A self-report questionnaire was filled out by participants to investigate how they perceived the effects of TBL.

\subsection{Design of the TBL}

Considering the results of Skehan et al. (2012), who contended that the "first use [of an exercise] is to prime later use and thereby to enable the speaker to exploit the greater accessibility of the language and avoid errors that were made the first time around" (p. 181), the current TBL worksheet was designed to include pre-task practices, (e.g. a warm-up) and pair/group discussions of reading, aimed to better equip students with the language skills required to verbally display their understanding and opinion for later task. (See Appendix A for the sample worksheets.) Repetition and language review were thus incorporated into a TBL lesson without appearing monotonous. Since the reading materials had been assigned as homework in the preceding week, the instructor did not go over them in class. Her role was typically limited to one of an observer or counsellor. After pre-task activities, students then performed given oral tasks followed by the feedback of the instructor and their peers. Due to limited time in the class session, every student giving an oral presentation was out of the question. After the instructor highlighted the relevant language areas to practice based upon what emerged from the task phase, students were accordingly required to record their oral tasks individually and upload the audio files onto their e-learning portfolios. Table 1 shows the framework of TBL.

Table 1. Structure of a TBL session

\begin{tabular}{|c|c|c|}
\hline Stages & Activities & Goals \\
\hline Warm-up & $\begin{array}{l}\text { Teacher eliciting life experiences of students } \\
\text { related to given reading texts }\end{array}$ & $\begin{array}{l}\text { To help students recall some language useful } \\
\text { for the task }\end{array}$ \\
\hline $\begin{array}{l}\text { Pair/Group } \\
\text { Discussion }\end{array}$ & $\begin{array}{l}\text { Students providing dialogues based on the reading } \\
\text { texts, exchanging opinions and learning to } \\
\text { negotiate }\end{array}$ & $\begin{array}{l}\text { To facilitate students' cognitive processes } \\
\text { such as selecting, classifying and evaluating } \\
\text { information in the reading text }\end{array}$ \\
\hline Task & Individual or group presentations & $\begin{array}{l}\text { To involve students in language use in the } \\
\text { real world and direct students' attention to } \\
\text { meaning-based learning }\end{array}$ \\
\hline $\begin{array}{l}\text { Teacher's } \\
\text { comments }\end{array}$ & $\begin{array}{l}\text { Teacher highlighting relevance in the reading text, } \\
\text { and giving feedback on students' performances } \\
\text { concerning content and grammar constructs }\end{array}$ & $\begin{array}{l}\text { To accent the language areas for students to } \\
\text { practice based upon what emerged from the } \\
\text { task phase }\end{array}$ \\
\hline $\begin{array}{l}\text { Recycling } \\
\text { practice }\end{array}$ & $\begin{array}{l}\text { Working on language areas emerging from the } \\
\text { tasks. }\end{array}$ & $\begin{array}{l}\text { To increase students' familiarity and fluency } \\
\text { and work on some grammar constructs }\end{array}$ \\
\hline
\end{tabular}




\subsection{Participant}

The participants consisted of 76 non-English majors, 34 men and 42 women, enrolled in two sections of a Freshman English course at a university in northern Taiwan. Their mean length of previous study of English was 11 years (range: 10-15, SD: 2.18). In terms of the students' proficiency, a majority of them were perceived to be intermediate $\mathrm{B} 2$ by their instructor.

\subsection{Student's Oral Presentations}

All of the students' oral presentations over the 15 weeks, including individual and group work, were audio-recorded for analysis. During the first and last week over the duration of the study, the task was recorded individually to assess the improvement of students. During the first week, students were required to improvise a 5-minute oral report on the reading text "Why I Quit the Company" (henceforth Recording W). During the last week, students were required to present an impromptu talk encompassing the main ideas of the newspaper article, "Shy to Spend, Young Japanese Hinder Deflation Battle" (henceforth Recording S).

\subsection{Evaluations on Recordings}

Without showing the dates, the recordings acquired during the first and last week of the study were evaluated by another English teacher (henceforth Teacher A) on a 10-point scale to evaluate the improvements of the learner over time. According to Skehan (2009), counting mid-clause pauses is a more sensitive measure of capturing differences in non-native speaker performance. Intonation and stress are essential measures for thought group and intelligibility. Three measures of fluency were adopted accordingly: intonation, stress, and mid-clause pauses. The other items to evaluate the linguistic development of students by Teacher A included syntactical complexity, accuracy and overall performance. Syntactical complexity indicated the occurrences of sentence patterns other than simple sentences. All quantitative analyses were carried out by EViews.

\subsection{Standardized Proficiency Tests}

The university where the research was conducted held biannually the general English proficiency test (GEPT) of intermediate level, usually scheduled at the end of each semester. The GEPT administered in the first semester was used as the pre-test of the experiment. After the implementation of TBL for 15 weeks in the second semester, another GEPT was administered as the post-test. The GEPTs contained two sections: listening and reading comprehension, full marks being 120 .

\subsection{Student's Self-Report Questionnaire}

A questionnaire was filled out by participants to investigate how the learners had perceived TBL and how this pedagogy helped direct their attention while focusing on meaning-based learning (see Appendix B). The questionnaire was mainly composed of statements measured on a five-point Likert Scale, ranging from 5 ("Strongly agree"), to 1 ("Strongly disagree") and two open-ended questions. Spaces were provided for additional comments.

\section{Results and Discussion}

\subsection{Effects of TBL on Language Development}

Table 2. Paired t-test for implement of TBL

\begin{tabular}{|c|c|c|c|c|c|}
\hline \multirow{2}{*}{$\mathrm{N}=76$} & \multicolumn{2}{|l|}{ Before } & \multicolumn{2}{|l|}{ After } & \multirow{2}{*}{$\mathrm{t}$} \\
\hline & $\mathrm{M}(\mathrm{SD})$ & Mode & $\mathrm{M}(\mathrm{SD})$ & Mode & \\
\hline Intonation & $6.11(1.25)$ & $6 /(4 \sim 10)$ & $8.34(1.15)$ & $8 /(5 \sim 10)$ & $-11.48 * *$ \\
\hline Stress & $6.13(1.25)$ & $6 /(3 \sim 9)$ & $7.63(1.33)$ & $8 /(5 \sim 10)$ & $-7.19 * *$ \\
\hline Mid-clause pauses & $2.25(0.90)$ & $2 /(1 \sim 5)$ & $0.62(0.78)$ & $0 /(0 \sim 3)$ & $-11.59 * *$ \\
\hline Syntactic complexity & $0.20(0.40)$ & $0 /(0 \sim 1)$ & $1.93(0.96)$ & $2 /(0 \sim 4)$ & $-14.60 * *$ \\
\hline Accuracy & $6.84(0.88)$ & $7 /(5 \sim 8)$ & $7.12(1.00)$ & $7 /(5 \sim 9)$ & -1.80 \\
\hline Overall & $6.71(0.99)$ & 7/(4 9) & $8.50(1.03)$ & $9 /(5 \sim 10)$ & $-10.94 * *$ \\
\hline GEPT Reading & $89.24(13.16)$ & $90 /(57 \sim 111)$ & $97.20(9.44)$ & $99 /(63 \sim 114)$ & $-4.29 * *$ \\
\hline GEPT Listening & $93.41(15.17)$ & $97 /(55 \sim 120)$ & $93.51(15.01)$ & $97 /(50 \sim 117)$ & -0.04 \\
\hline
\end{tabular}

$* *$ p $<.001$. 


\subsubsection{Greater Fluency}

Tables 2 demonstrates that students improved significantly in terms of intonation, stress, and fewer mid-clause pauses after TBL, [intonation $\mathrm{t}(75)=-11.48, \mathrm{p}<.001$, stress $\mathrm{t}(75)=-7.19, \mathrm{p}<.001$, mid-clause pauses $\mathrm{t}(75)=-11.59$, $\mathrm{p}<.001]$. As aforementioned, the three items are the measurements for fluency. Through TBL, students spontaneously incorporated intonation and stress when engaging in meaningful discourse with their peers. After approximately four weeks of the task when students had achieved a level of comfort in English communication, whispers and murmurs that had prevailed during the first few weeks of the study like "It's your turn," "I am so nervous", or "Mm, how to say it" were overheard infrequently. Moreover, as shown in Table 2, Mode changed from $6 /(4 \sim 10)$ to $8 /(5 \sim 10)$ for intonation, and changed from $2 /(1 \sim 5)$ to $0 /(0 \sim 3)$ for mid-clause pauses, which indicates the differences of students in mid-clause pauses and intonation became smaller than in the other domains after TBL.

\subsubsection{Significant Increase in Lexical Sophistication and Syntactic Complexity}

During the first few weeks of the study period, the learners were incapable of using a variety of vocabulary. Despite fully understanding what they had read, the learners seldom "borrowed" words/phrases from the reading text. Their strategy was to use a very basic level of vocabulary that was familiar to them, sometimes at the cost of fully expressing themselves. This was evidenced by the remarks of Teacher A on Recordings W (during week 1):

"The vocabulary students were capable of using in their oral presentations was limited, which hindered them from fully expressing their ideas. Considering the words that were presumably known by the university students, they should have been able to verbalize more advanced vocabulary. However, the vocabulary at their disposal was, disappointingly, basically what they had learned in junior high school. I am not stating that the students could not do well without the use of more complex words, but the fact is that they have difficulty even expressing a simple idea using basic-level vocabulary."

As the research progressed into week 5, however, lexical developments were observed; synonyms and derivatives other than the key words provided in the reading text as well as more complex adjective phrases were attempted. In her comments on Recordings S (during week 15), teacher A shed light on the perceived improvements:

"There was more meaningful and concrete content in these recordings than in Recordings W. Compared with the overused beginner-level vocabulary like 'happy', 'wonderful', exciting', and 'funny', the vocabulary used in the assignments is delightfully varied."

In general, English and Mandarin have the same basic word order of subject-verb-object (Li \& Thompson, 1981; Huang \& Chui, 1997). In this study, syntactic complexity referred to the occurrence of sentences that did not resemble the Chinese syntax. Two examples of this are the relative clause and the third conditionals (unreal in the past). In the first few weeks, students constructed English sentences that resembled those using Chinese syntax. During the fifth week of this study, 19 students (25\%) began to include relative clauses in their oral presentations. As research progressed into the ninth week, 37 students $(49 \%)$ were capable of producing relative clauses verbally. During the 14th week, 29 students started constructing sentences of the third conditionals while discussing the economic reforms of Japanese Prime Minister, Abe. These may be regarded as major indicators of syntactic improvement. Table 3 shows the significant syntactical achievement.

Table 3. Syntactical achievements in oral presentations over 15 weeks

\begin{tabular}{lll}
\hline Week & Syntactical achievements & Usage \\
\hline $1-2$ & Dominant simple sentences; sporadic adverb clauses & S-V-O; when-, although-, and because clauses \\
3 & More adverb clauses & First conditionals \\
4 & Indirect questions & Used as the subject and the object \\
5 & Relative clauses & Characterization \\
7 & Passive & Replacements for S-V-O structure. \\
$9-10$ & More occurrences of the relative clauses & Defining terms \\
12 & Prepositional phrases & Used as the adjectives \\
14 & The third conditionals & Talking about unreal condition in the past \\
\hline
\end{tabular}




\subsubsection{Modest Gains in Accuracy}

The term "accuracy" addresses grammatical correctness and appropriate diction. Table 2 demonstrates modest gain in accuracy $[\mathrm{t}(75)=-1.80]$. Compared with the other items investigated in this study, gains in accuracy were not obvious. This phenomenon may be due to fossilized errors that were so ingrained in the learners that they became a part of their natural speech. Teacher A provided the following comment on this matter:

"Students repeatedly made the same errors in both recordings. Common errors including incorrect verb tenses as well as the use of two verbs in a sentence (e.g., there are ... V) recurred in both sets of recordings."

\subsubsection{Significant Improvement in Reading and Little Improvement in Listening of the GEPT}

As shown in Table 2, students improved significantly in reading [Mbefore $=89.24$, Mafter $=97.20, t(75)=-4.29$, $\mathrm{p}<.001$ ] and improved insignificantly in listening [Mbefore $=93.41$, Mafter $=93.51, \mathrm{t}(75)=-0.04$ ]. This result is likely because the texts used in the study were mainly reading texts. If they had been listening texts, the opposite results might have been obtained. Compared with the test results of the other freshman students of this university, [Mbefore=78.13, Mafter=75.46 in listening, Mbefore=73.60, Mafter=79.21 in reading], participants made significant improvements on the proficiency tests. Moreover, the significant improvement in reading was presumably related to the learning motivation of students. To engage in meaningful discourse with their peers, students were required to fully comprehend a reading text. To complete their individual oral task and upload it onto their e-learning portfolio in time, students skimmed relevant reading materials in class and thus their reading skills were enhanced over time. As to the modest improvement in listening of the GEPT, it was likely because students accustomed to listening to their EFL classmates had problems with the speech speed and the contraction of authentic spoken English. It is suggested that listening texts be included in TBL materials in the future.

\subsection{Students'Perception of TBL}

Table 4. Results of students' questionnaire

\begin{tabular}{lc}
\hline Questionnaire Item & M(SD) \\
\hline 1) TBL is motivational for learning English. & $3.89(0.77)$ \\
2) TBL is useful for learning English. & $3.63(0.66)$ \\
3) Through TBL, I paid more attention to the reading text as a whole, not just for learning & $3.84(0.57)$ \\
vocabulary and grammar. & $4.28(0.25)$ \\
4) My linguistic limitation did not permit my clear self-expression in English before TBL. \\
5) After TBL, I got a sense of comfort in communicating in English.
\end{tabular}

5=Strongly agree, 4=Agree, 3=Neutral, 2=Disagree, 1=Strongly disagree.

\subsubsection{More Comfort in Speaking English after TBL}

As shown in Table 4, participants reported in the questionnaire that TBL was motivational $[\mathrm{M}(\mathrm{SD})=3.89(0.77)]$ and useful $[\mathrm{M}(\mathrm{SD})=3.63(0.66)]$. Some of these learners expressed an enjoyment of TBL, partly because they "could speak English instead of sitting there and listening to the teacher," and partly because "they had seldom spoken English with their classmates during class." Both Long's interactionist hypothesis (1981) and Kashan's input hypothesis (1985) contended that acquisition is autonomous and learner-driven. From a communicative perspective, language is best learned when used, especially orally, which better allows learners to retain the language. Students also claimed that TBL helped retain the language and that they got a sense of comfort in communicating in English. $[\mathrm{M}(\mathrm{SD})=3.71(0.74))$. A student pointed out how she benefited from TBL:

"The best thing is that I remember many new words and phrases for a longer time because I really use them for communicative purposes, not just for the exam. With more oral practice with my group members, I feel more conformable about speaking English."

\subsubsection{Attention Directed to Language Expression}

It is noteworthy that these students, who had been accustomed to test-driven pedagogy in high school, acknowledged linguistic limitations that often did not permit their clear self-expression $[\mathrm{M}(\mathrm{SD})=4.28(0.25)]$. TBL increased learners' awareness of the disparity between conceptual content and language expression. Below 
is a typical student comment on TBL:

"I comprehended the article thoroughly, but while speaking in English, I often paused and didn't know how to continue. I could just say, "I... I...I..." Now, I am aware that I should not merely understand the reading text but should also be able to provide an opinion in English."

3.2.3 Attention to Collocation

Table 5. Students' perception of effects of TBL on linguistic acquisition

\begin{tabular}{ll}
\hline Items investigated for linguistic acquisition & $\mathrm{M}(\mathrm{SD})$ \\
\hline Pronunciation & $3.52(0.31)$ \\
Vocabulary & $3.43(0.46)$ \\
Collocation & $3.25(0.64)$ \\
Grammar & $2.45(0.99)$ \\
\hline
\end{tabular}

$5=$ Very useful, 4=Useful, 3=Neutral, 2=Not useful, 1=Useless.

In the self-assessment of the effects of TBL, most participants felt improvements in pronunciation, vocabulary, and attention towards proper collocation. Table 5 shows the mean scores were 3.52( $\mathrm{SD}=0.31), 3.43(\mathrm{SD}=0.46)$ and $3.25(\mathrm{SD}=0.64)$ respectively. One domain where students perceived little effect was grammar, $\mathrm{M}(\mathrm{SD})=2.45(0.99)$. For students used to test-oriented pedagogy, TBL may appear insufficient with respect to grammatical drills.

Across the literature, very few studies have investigated on the effects of TBL on collocation among EFL learners. In the study, some students claimed that their attention was directed toward collocation, $\mathrm{M}(\mathrm{SD})=3.25(0.64)$. Several participants in the study further pointed out how their awareness of collocation was raised by TBL:

"I used to overlook collocation when I read, especially the association between the verb and the noun. In the group discussion, I found that I didn't know which verb was correct, so I looked up for assistance. For example, I should say 'create a website,' not 'open a website'. I should say 'to have plastic surgery,' instead of 'get a plastic surgery.' And the correct verbs for kung fu are 'know' and 'do'. For example, 'He knows kung fu,' 'He is doing kung fu."”

\section{Conclusion}

Since students had not enrolled in courses like English Listening Practice or English Conversation during the study period, and the language used in the other classrooms was mainly L1, the participants' linguistic development in English may be closely related to the pedagogy implemented in this study. In our qualitative and quantitative analyses, we corroborated that TBL was effective in developing the English verbal competence of learners. This learner-driven pedagogy helped raise students' awareness of the disparity between conceptual material and language expression. Students improved in terms of fluency as well as lexical and syntactical complexity. The differences of students in intonation and mid-clause pauses became smaller than in the other domains in relation to fluency after TBL. When more lexical and syntactic sophistication was developed, more concrete and meaningful content was presented. Despite the insignificant improvement in accuracy as perceived by Teacher A, common mistakes in comparatives (e.g. more happier, more easier) and in conjunctions (e.g. two conjunctions connecting two sentences) were heard infrequently from the students' e-learning portfolios. It suggested that the recycling practice was likely a factor that contributed to students' better performances. Some students also reported that their attention was directed to collocation. For students who had been accustomed to test-driven pedagogy in high school, TBL helped direct their attention to reading texts as a whole for communicative purposes. Considering the results for the standardized proficiency tests, the significant improvements in reading demonstrated that TBL is an effective technique for facilitating English language acquisition. It is suggested that listening texts be also used in the EFL class in the future to help enhance listening competence of learners. Although some students felt TBL insufficient for grammatical drills, better learning outcome in this regard may be obtained when reading texts are purposefully selected. Overall, the findings of this study supported the proposition that language was better learned when orally used. TBL allowed the students to experience joy and sense of accomplishment when they relayed their message and thus became motivational, and therefore their receptive and productive competence was enhanced. 


\section{References}

Breen, M. (1989). The evaluation cycle for language learning tasks. In R. K. Johnson (Ed.), The foreign language curriculum (pp. 187-206). Cambridge: Cambridge University Press.

Bruner, D. A., Sinwongsuwat, K., \& Radić-Bojanić, B. (2015). EFL oral communication teaching practices: A close look at university teachers and A2 students' perspectives in Thailand and a critical eye from Serbia. English Language Teaching, 8(1), 11-20. Retrived from http://dx.doi.org/10.5539/elt.v8n1p11

Bygate, M. (1999). Quality of language and purpose of task: Patterns of learners' language on two oral communication tasks. Language Teaching Research, 3(3), 185-214. Retrieved from http://tr.sagepub. com/content/3/3/185.refs.html

Bygate, M., Skehan, P., \& Swain, M. (2001). Introduction. In M. Bygate, P. Skehan, \& M. Swain (Eds.), Researching pedagogic tasks: Foreign language learning, teaching, and testing (pp. 1-20). Harlow, UK: Longman.

Ellis, R. (2003). Task-based language learning and teaching. Oxford: Oxford University Press.

Huang, S., \& Chui, K. (1997). Is Chinese a pragmatic order language? Chinese language and linguistics: Typological studies of language in China, 4, 51-79.

Kouraogo, P. (1993). Language learning strategies in input-poor environments. System, 21(2), 165-173.

Krashen, S. (1985). The input hypothesis: issues and implications. London: Longman.

Li, C. N., \& Thompson, S. (1981). Mandarin Chinese: A functional reference grammar. Berkeley: University of California Press.

Long, M. H. (1981). Input, interaction, and foreign language acquisition. In H. Winitz (Ed.), Native language and foreign language acquisition, Annals of the New York Academy of Sciences, 379, 259-278.

Lynch, T., \& Maclean, J. (2000). Exploring the benefits of task repetition and recycling for classroom language learning. Language Teaching Research, 4(3), 221-250. Retrieved from http://ltr.sagepub.com/content/4/3/221.refs.html

Park, S. (2010). The influence of pre-task instructions and pre-task planning on focus on form during Korean EFL task-based interaction. Language Teaching Research, 14(1), 9-26. Retrieved from http://dx.doi.org/10.1177/1362168809346491

Scheffler, P. (2012). Theories pass. Learners and teachers remain. Applied Linguistics, 33(5), 603-607. Retrieved March 8, 2014, from http://applij.oxfordjournals.org/10.1093/applin/ams062

Skehan, P. (2009). Lexical performance by native and non-native speakers on language-learning tasks. In B. Richard, H. Daller, D. D. Malvern, \& P. Meara (Eds.), Vocabulary studies in first and foreign language acquisition: The interface between theory and application (pp. 107-124). London: Palgrave Macmillan.

Skehan, P., Bei, X., Li, Q., \& Wang, Z. (2012). The task is not enough: Processing approaches to task-based performance. Language Teaching Research, 16(2), 170-187. http://tr.sagepub.com/content/ 16/2/170.refs.html

Springer, S., \& Collins, L. (2008). Interacting inside and outside of the language classroom. Language Teaching Research, 12(1), 39-60. http://tr.sagepub.com/content/12/1/39.refs.html

Swan, M. (2005). Legislation by hypothesis: The case of task-based instruction. Applied Linguistics, 26(3), 376-401. Retrieved March 8, 2014, from http://applij.oxfordjournals.org/10.1093/applin/ami013

Ur, P. (2013). Language-teaching method revisited. ELT Journal, 67(4), 468-474. Retrieved from http://eltj.oxfordjournals.org/content/67/4/468.abstract

\section{Appendix A}

\section{Worksheet 1. Why I Quit the Company}

Warm-up

1) How do you spend an average week?

2) What are factors to consider when you are choosing a job?

Pair Work 
1) Develop a dialogue between Iwashita and her supervisor based on the reading.

2) Develop a dialogue between Iwashita and her co-worker who is unable to quit for financial reasons.

Group Discussion

1) What kind of girl do you think Iwashita is?

2) Would you like to work for the company described in the article? Why or why not?

Task

Log onto HelpWanted.com and look for a job for Iwashita. Explain why the job fits her.

Worksheet 15. Shy to Spend, Young Japanese Hinder Deflation Battle

Warm-up

1) How much do you spend weekly? What do you mostly spend on?

2) What do you usually buy with your savings?

Pair Work

1) What is deflation? Would you spend or save money during the times of deflation?

2) How does deflation affect a country?

Group Discussion

1) How does Japanese mindset hinder Abe's deflation battle?

2) Develop a dialogue between Abe, prime minister of Japan, and young Japanese who are shy to spend based on the article.

Task

Search the pros and cons of spenders and savers online and then provide advice to young Japanese.

\section{Appendix B}

Student Self-report Questionnaire

\begin{tabular}{llllllll}
\hline Items & 5 & 4 & 3 & 2 & 1 & Reasons
\end{tabular}

1) TBL is motivational for learning English.

2) TBL is useful for learning English.

3) Through TBL, I paid more attention to the reading text as a whole, not just for learning vocabulary and grammar.

4) My linguistic limitation did not permit my clear self-expression in English before TBL.

5) After TBL, I got a sense of comfort in communicating in English

6) TBL was effective for learning vocabulary and idioms.

7) TBL helped direct my attention to collocation.

8) TBL was useful for learning grammar.

9) Through TBL with my peers, I improved in pronunciation.

10) TBL enhanced my reading skills.

11) How did TBL differ from your previous learning experience?

12) Please provide suggestions for the class in the future.

5=Strongly agree, $4=$ Agree, $3=$ Neutral, $2=$ Disagree, 1=Strongly disagree.

\section{Copyrights}

Copyright for this article is retained by the author(s), with first publication rights granted to the journal.

This is an open-access article distributed under the terms and conditions of the Creative Commons Attribution license (http://creativecommons.org/licenses/by/3.0/). 